$\xi=1$

\title{
Description of an educational programme developed to support registered nurses during clinical supervision of student nurses in medical and surgical wards in a training health facility: Namibia
}

\author{
Hanna Neshuku *, Amukugo Hans Justus \\ Lecturers, School of nursing, Faculty of health Sciences University of Namibia \\ *Corresponding author E-mail: hneshuku@unam.na
}

\begin{abstract}
This paper describes an educational programme interventions developed to support registered nurses during the clinical supervision of student nurses in the medical and surgical wards of a training hospital in the Oshana region, Namibia.

The programme developed contained the purpose and goals of the programme, programme objectives, programme structure, processes and approaches. The programme catered for the following themes: Managerial challenges, educational challenges and non-conducive environment as was experienced by registered nurses and student nurses in order to support them during clinical supervision. It includes the activities to address managerial challenges as identified to be affecting the clinical supervision of student nurses; this is to address educational challenges identified during clinical supervision of student nurses. Furthermore, the programme contains activities focused on providing registered nurses with knowledge and skills on clinical supervision, in order to increase their understanding and competence about the clinical supervision of student nurses. Another activity included interventions for enhancing positive interpersonal relationships and good communication skills to improve effective interactions between registered nurses and student nurses. This study made it possible for the development of an educational programme that enable the registered nurses to receive the much needed information pertaining to the clinical supervision of student nurses, and served as a guide and support tool when carrying out clinical supervision of student nurses.

In conclusion the study was justified as an original contribution to the existing body of knowledge in general health nursing science.
\end{abstract}

Keywords: Educational Programme; Intervention; Support; Clinical Supervision.

\section{Introduction}

A programme is defined as an officially organized system of a series of activities or opportunities that help people to achieve something (Cambridge Academic Content Dictionary, 2009). This is in line with Webster (2009.) who defines a programme as a brief, usually printed outline of the order to be followed or features to be presented; plan of things that are done to achieve a specific result.

An educational programme is defined as a programme for education. Educational programmes are constructed opportunities for learning that can be re-designed to improve healthy literacy. For this study, an educational programme refers to compiled learning activities that will support supervisors with knowledge and skills in order for them to be able to provide effective clinical supervision to student nurses.

\section{Research method}

A research method is defined as a systematic set of techniques and procedures followed by a researcher when collecting and analysing data. It refers to the particular steps, advanced procedures, and strategies used by the researcher when collecting and analysing data during the research process (Babbie \& Mouton, 2009). Effective research methods ensure that a research question is answered as reliably as possible with the purpose of achieving the objectives of a study (Creswell, Rocco \& Hachert, 2011). For this study, individual in-depth interviews were conducted. The researcher kept written records of all the observations made and noticed during each interview and a voice recorder was used to capture all information during each interview. Figure 1.3 illustrates the research phases of for this study. 


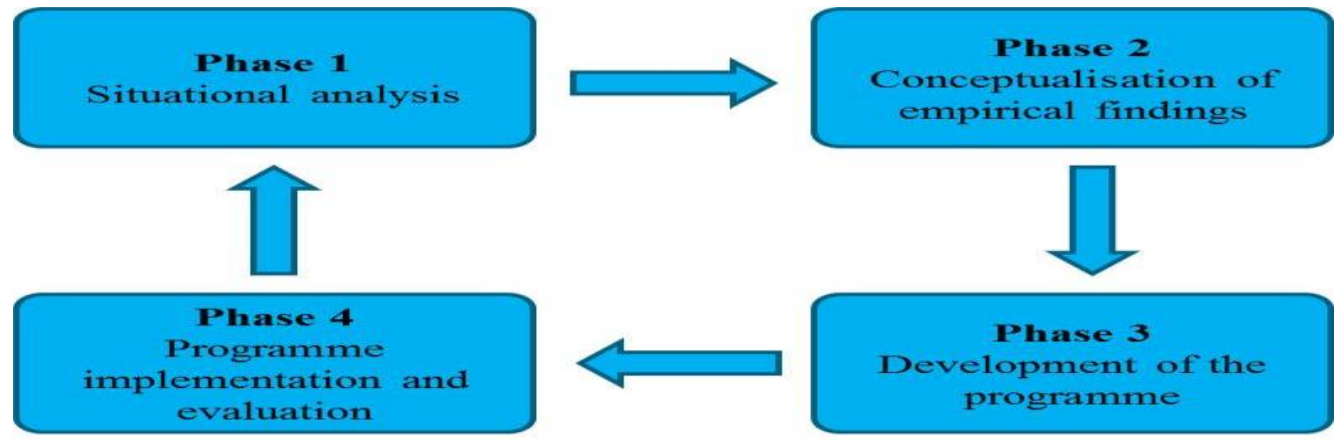

Fig. 1: Illustration of Research Phases of the Study

This study was conducted in four phases, namely a situation analysis, development of the conceptual framework, programme development, and a programme implementation and evaluation.

- Phase 1: Situation analysis: Phase 1 comprised the situation analysis that explored and described the experiences of nursing students and registered nurses in relation to the clinical supervision of nursing students.

- Phase 2: Development of the conceptual framework: Phase 2 was dealt with the development of a conceptual framework for the development of an educational programme to support registered nurses during the clinical supervision of nursing students.

- Phase 3: Programme development: During this phase of the study, an educational programme to support registered nurses during clinical supervision was developed guided by the results of the situation analysis and the conceptual framework (Dickoff, James \& Wiedenbach, 1968).

- Phase 4: Programme implementation and evaluation: Firstly, the educational programme interventions that were developed to support registered nurses during clinical supervision of nursing students were implemented during this phase.

Secondly, the educational programme was evaluated in order to validate whether the programme interventions were likely to bring about the desired change among the participants or whether the programme intervention could be generalised to another situation with a similar context.

\section{Description of the programme}

The data analysis revealed that registered nurses and nursing students were encountering managerial and educational challenges during the clinical supervision of nursing students and the clinical environment was not conducive for the clinical supervision of nursing students. After analysing the data and formulating a conceptual framework, the researcher resolved to institute the intervention of developing an educational programme to support registered nurses during clinical supervision of nursing students.

The programme development constituted Phase 3 of this study and was based on the survey guide suggested by Dickoff et al. (1968). The researcher was guided by the six survey components (Chapter 4). The programme was also developed in line with the educational the crucial expectation that a programme should have a specific focus based on a needs assessment and outcome or findings (Watson, 2011). The needs assessment done during Phase 1 (situation analysis) provided a foundation for the development of this educational programme. The programme developed contained the purpose and goals of the programme, programme objectives, programme structure, as well as participants' roles and responsibilities, activities, processes, and approaches.

\subsection{Purpose of the educational programme}

Educational programmes are developed to serve a specific goal based on the need assessment (Watson 2011). The purpose of this programme was to address challenges experienced by student nurses and registered nurses during clinical supervision of student nurses in medical and surgical wards of training health facility in Oshana region, Namibia, in order to support them to provide effective clinical supervision of student nurses in their specific context. as follows: Firstly to address the managerial challenges identified as affecting the clinical supervision of student nurses in order to support registered nurses during clinical supervision of student nurses. Secondly to address educational challenges by providing registered nurses with knowledge and skills regarding the concept of clinical supervision. And lastly to address nonconducive environment through teaching and motivation on constructive interpersonal relationships among registered nurses and between registered nurses and student nurses, that promotes effective clinical supervision of student nurses by registered nurses.

\subsection{Objectives of the programme}

The objectives of the programme developed are to address:

- The managerial challenges experienced by student nurses and registered nurses during clinical supervision of student nurses in order to support registered nurses during clinical supervision of student nurses. This objective is intended to cater for the experiences of managerial challenges by registered nurses and student nurses who are: too heavy a workload; lopsided supervisor/student ratio; no clinical instructors in some wards which hamper the execution of effective supervision.

- The educational challenges experienced by student nurses and registered nurses during clinical supervision of student nurses in order to support registered nurses during clinical supervision of student nurses. This objective is intended to cater for the following themes: Educational challenges which include lack of knowledge about the concept clinical supervision, lack of knowledge on supervision roles; outdated supervisors; gap between theory and practice as experienced by both registered and student nurses during clinical supervision.

- Non-conducive environment experienced by student nurses and registered nurses during clinical supervision of student nurses in order to support registered nurses during clinical supervision of student nurses. This objective is intended to cater for the following themes: To create a conducive environment and enhance constructive interpersonal relationships among registered nurses and between registered nurses and student nurses that promotes effective clinical supervision which under the following subthemes; poor interpersonal relationships and poor communication among the supervisors and between supervisors and student nurses; poor guidance of student nurses by registered nurses as well as material shortages which affect the process of clinical supervision negatively.

\subsection{Programme structures}

The programme was developed to run for two days and it was designed to be implemented in the form of a workshop. The work- 
shop was planned to be conducted at the University of Namibia Oshakati campus at the library board room.

\subsection{Programme processes}

The educational programme developed was a three-phase process, consisting of an orientation phase, a working phase and a termination phase.

\subsection{Educational approaches}

Table 1: An Educational Programme to Support Clinical Supervision of Nursing Students by Registered Nurses in the Medical and Surgical Wards at Training Health Facilities in the Oshana Region, Namibia

\begin{tabular}{|c|c|}
\hline Aspect & Description \\
\hline Programme objectives & $\begin{array}{l}\text { - To address the managerial and educational challenges identified as affecting the clinical supervision } \\
\text { of nursing students in order to support registered nurses during clinical supervision of nursing stu- } \\
\text { dents. } \\
\text { To address educational challenges by providing registered nurses with knowledge and skills in rela- } \\
\text { tion to the concept of clinical supervision. } \\
\text { To address a non-conducive environment through teaching and motivation about constructive inter- } \\
\text { personal relationships among registered nurses and between registered nurses and nursing students } \\
\text { that promote effective clinical supervision of nursing students by registered nurses. }\end{array}$ \\
\hline Programme structure & The programme is developed to be implemented in the form of a workshop \\
\hline Programme approaches & Kolb learning theory and adult learning approach \\
\hline Programme phases & Orientation phase, working phase, and termination phase \\
\hline
\end{tabular}

Objectives and guidelines to cater for each objective are illustrated in figure 1 below;

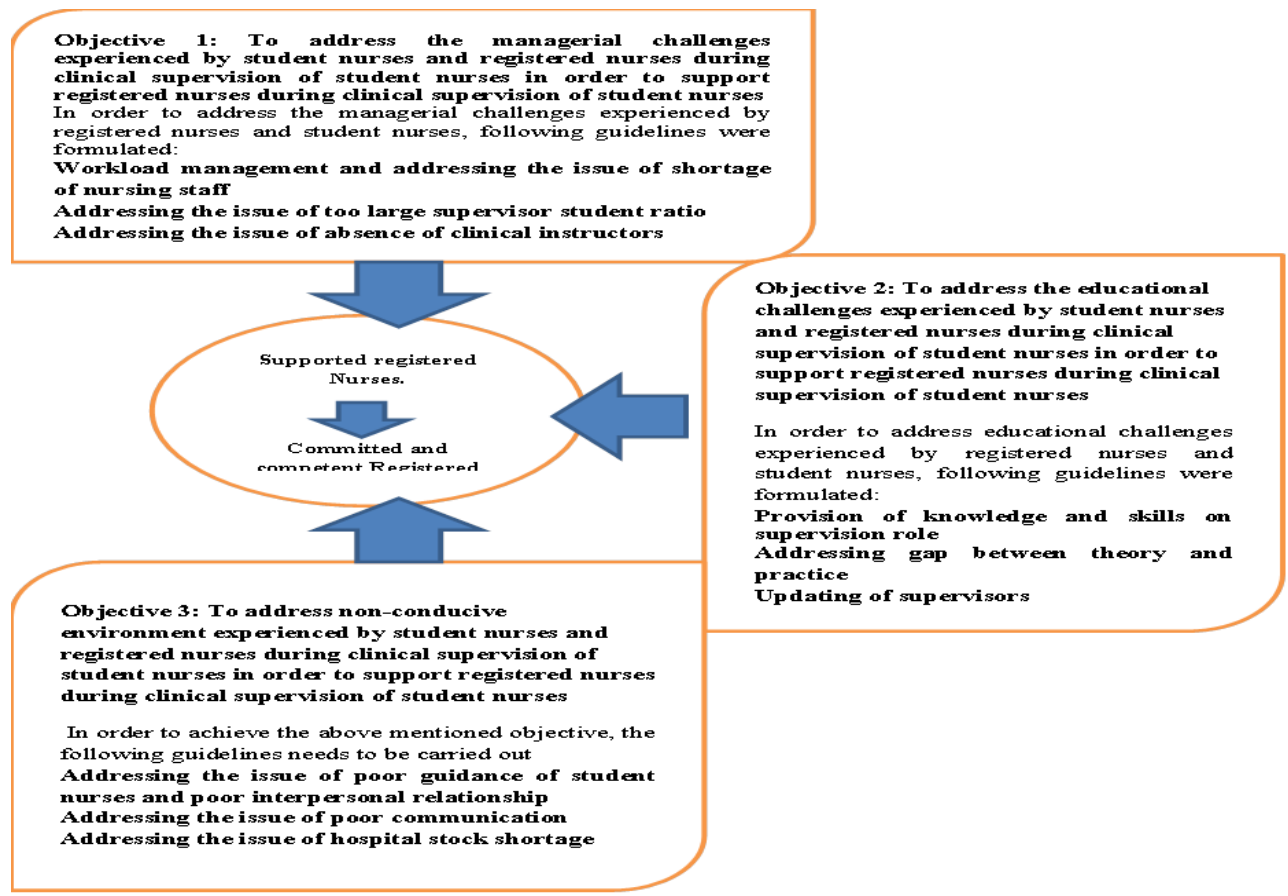

Fig. 2: Objectives and Guidelines to Address Challenges Experienced by Registered Nurses in Medical and Surgical Wards in Training Health Facility in Oshana Region, Namibia

Description of an educational programme based on the programme objectives and guidelines which were formulated.

Objective 1: Addressing the managerial challenges identified as affecting the clinical supervision of nursing students in order to support registered nurses during clinical supervision of nursing students

In order to address the managerial challenges experienced by registered nurses and nursing students, the following guidelines were formulated:

- Workload management and addressing the issue of the nursing staff shortage.
The educational approaches to the programme took cognizance of the experiential learning within the paradigm of adult learning, as suggested by Smith (2004). Experiential learning refers to learning opportunities where participants learn from and through personal and group experience and by reflecting on what has been learned (Smith, 2004). The focus in experiential learning is on building on existing strengths and on the life experiences of the participants.

The content of an educational programme which was developed is illustrated as table 1 below 
Registered nurses should delegate the responsibility and authority when it possible. It also involve time management through effective planning and scheduling of the work time to insure that the most important work is completed and that sufficient time is allowed for unexpected emergencies and crises that may occur during the facilitation process Registered nurses need to keep a time $\log$ of their activities (Booyens 2005)

- Addressing the unavailability of clinical instructors. Consensus decision-making: Registered nurses should have time to debate and agree on the who, how, and when of clinical supervision. Negotiation: There should be a regular platform for individual supervisors, hospital management and training health professionals to deliberately meet with the aim of reaching a jointly acceptable agreement about the clinical supervision of nursing students.

Objective 2: Address educational challenges by providing registered nurses with knowledge and skills with regard to the concept of clinical supervision

To overcome those challenges following activities need to be carried out for the facilitation of the following guidelines (Van Ooijen 2000, Bezuidenhout 2003)

- Provision of knowledge and skills about the supervision role.

To educate, train, and disseminate information by providing registered nurses with basic knowledge, skills about morals and values, and an understanding of clinical supervision. The supervisors need to have knowledge and skills about clinical supervision that includes the following topics: Definitions of models and components of clinical supervision; core content of supervision interventions; qualities, roles, and responsibilities of a supervisor; and supervisor preparation (Kaviani \& Stillwell 2000, Ohring \& Hallberg 2001). Training and educating methods should be used during the acquisition of knowledge and skills. These methods could be group discussions, role playing, lecturing, group discussion, counselling, and demonstrations. There should be adequate and effective training and educational materials to be used during the process.

- Addressing the gap between theory and practice.

Strategies for conflict management included mechanism on how to approach conflict caused by the gap between theory and practice through corroboration between those who are providing theory and supervisors of practice. Through collaboration different perspective are examined, new ideas and possibilities are explored and common knowledge derived can be used to reach the conclusion on how to tackle this problem. Fostering of the integration of theory and practice need to be emphasised.

- Updating of supervisors (Hinchliff 2005).

Training and education should be formal or informal which could take place in wards or lecture halls at the health facility or elsewhere.

Objective 3: To address non-conducive environment through teaching and motivation in relation to constructive interpersonal relationships among registered nurses and between registered nurses and nursing students that promote effective clinical supervision of nursing students by registered nurses.

These objectives aim at creating interpersonal relationships and among the registered nurses and between registered nurses and nursing students by increasing self-awareness, openness, trust, communication, receptiveness and motivation. An effective environment for clinical supervision and clinical learning includes a physical environment to deliver quality care and facilitate the development of competencies. It should provide teaching and learning opportunities, resources, space, and referral materials that enhance teaching and learning. An effective environment for clinical supervision is characterised by a humanistic approach to students during clinical supervision (Quinn, 2000). There must be a sound leadership who values the education of nursing students and provides direction for registered nurses by promoting a conducive environment, trust, respect, and support for colleagues and nursing students. In order to achieve the abovementioned objectives, the following guidelines need to be implemented:
- Addressing the issue of poor guidance of nursing student's nurses and poor interpersonal relationships.

Building trust and relationships among registered nurses and between registered nurses and nursing students through showing interest in supervision, and listening to student needs and goals. Registered nurses collectively to putting issues on the table, creating a comfortable environment for the expression of all possible points of view regarding clinical supervision. Developing agreements regarding clinical supervision, implementing the agreed plan of action, monitoring progress, and maintaining working relationships (Kilmester, Cotrell, Grant and Jolly 2007).

- Addressing the issue of poor communication.

An effective communication process should involve the exchange of strategic information, thoughts, ideas, or motions in a comprehensive and productive manner. Communication should be a twoway process during which all the stakeholders actively participate and are involved in discussion until consensus is reached. Communication content should be clear, simple, and open with the purpose of facilitating the same understanding and interpretation of the message. The use of common language should facilitate continual interpersonal dialogue, shared meaning, understanding, interpretation, and accurate analysis of the communicated information. The communication process should be relevant, comprehensive, and timely.

- Addressing the issue of hospital stock shortages.

This can be achieved through mobilisation of material needed for clinical supervision; emphasising stock control and stock management strategies and Consultation meeting between registered nurses and hospital management to discuss hospital stock control (Royal College of Nursing, 2002, (Hinchliff 2005).

\subsection{Description of the implementation of the pro- gramme}

The programme was implemented in three phases. Phase $1 \mathrm{com}-$ prised the introductory phase. The working phase which in turn consisted of three sessions, and lastly, Phase 3 covered the termination phase. During the termination phase, all the issues related to registered nurses' experiences during the implementation of the programme were summarised and reflected upon. The programme phases are illustrated as table 2 .

Table 2: The Programme Phases

\begin{tabular}{|c|c|}
\hline Phase & Description \\
\hline \multirow{4}{*}{$\begin{array}{l}\text { Orientation } \\
\text { phase }\end{array}$} & Welcoming of the participants \\
\hline & Introduction of the workshop \\
\hline & Discussion of the purpose and objectives of the workshop \\
\hline & Establishment of workshop rules \\
\hline \multirow{3}{*}{$\begin{array}{l}\text { Working } \\
\text { phase }\end{array}$} & $\begin{array}{l}\text { Activities to address the managerial and educational } \\
\text { challenges identified as affecting the clinical supervision } \\
\text { of nursing students in order to support registered nurses } \\
\text { during clinical supervision of nursing students }\end{array}$ \\
\hline & $\begin{array}{l}\text { Activities to provide registered nurses with knowledge } \\
\text { and skills in relation to the concept of clinical supervision }\end{array}$ \\
\hline & $\begin{array}{l}\text { Activities to create a conducive environment and enhance } \\
\text { constructive interpersonal relationships among registered } \\
\text { nurses and between registered nurses and nursing stu- } \\
\text { dents that promote effective clinical supervision }\end{array}$ \\
\hline Termination & Evaluation and feedback on the training outcomes \\
\hline phase & Closing of the workshop \\
\hline
\end{tabular}

\subsection{Programme approaches}

Programme approaches applied in this educational programme are as follow:

Adult learning approach: The programme developed in such a way that it allows, they opportunity to self-direction and taking of responsibility for own decisions based on the information to be gained during the implementation of the programme.

On the other hand, the researcher regarded registered nurses as adult learners with knowledge and skills and they needed to share 
that knowledge with the purpose of contributing to the topic presented to the other participants.

Kolb's learning theory: Concrete experience: The participants were going to expected to gain new knowledge and values during group discussions and self-explorations based on PowerPoint presentations; therefore, they were encouraged to listen attentively during the presentations.

Kolb's learning theory: Active experimentation: Active experimentation encouraged the participants to practically test concrete learning. Therefore all participants were expected to actively take part in group discussions and during the role play; as well as in group feedback

\section{Conclusion}

This study made it possible for the development of an educational programme that enable the registered nurses to receive the much needed information pertaining to the clinical supervision of student nurses, and served as a guide and support tool when carrying out clinical supervision of student nurses.

\section{Acknowledgment}

The University of Namibia (UNAM) and Ministry of Health and Social Services, Namibia are gratefully acknowledged for granted me the permission for this kind of professional discourses.

The hospital management for the Oshakati Intermediate Hospital for creating conducive environment enable me to conduct this study as well as for any kind of support offered to me during this study.

Special acknowledgement is accorded to all registered nurses and nursing students who had taken part in this study, for their contributions and co-operation that made this study possible.

\section{References}

[1] Cambridge Academic Content Dictionary. (2009). Cambridge: Cambridge University Press.

[2] Webster, S.B. (2009). Qualitative research a guide to design and implementation ( ${ }^{\text {rd }}$ Ed.). San Francisco: John Willey \& Sons.

[3] Babbie, E. \& Mouton, J. (2009). The practice of social research (9th Ed.). Belmont. Wadsworth

[4] Creswell J.W., Rocco T.S. \& Hachert, T. (2011). The handbook of scholarly writing and publishing. San Francisco: John Willey and Sons.

[5] Dickoff, J., James, A. \& Wiedenback. (1968). Theory in a practice discipline. Part 1; practice oriented theory. Nursing Research 17(5), 415- 435. http://dx.doi.org/10.1097/00006199-196809000-00006.

[6] Watson E., 2011 System approach workbook for health education and program planning Sudbury: Jones \& Barlet

[7] Smith, M.K. (2004). David A. Kolb on experiential learning. The encyclopedia of Informal Education. Social Sciences method. Vol.41. Thousand Oaks: Sage.

[8] Booyens S.W. (2005). Dimension of Nursing Management. Juta \& Co. LTD: Lansdowne S.A.

[9] Van Ooijen, E. (2000). Clinical supervision in practical guide. Edinburg: Churchill Livingstone.

[10] Bezuidenhout, M.C. (2003). Guideline for enhancing clinical supervision. Health SA Gesondheid, 8(4):12-23. http://dx.doi.org/10.4102/hsag.v8i4.142.

[11] Kaviana, N.; Sillwell Y 2000 An evaluation study of clinical preceptorship. Nurse Education Today, 20:3 .218-226

[12] Ohrling K Hallberg I 2001 the meaning of perceptorship: Nurse 'lived experience of being preceptor. Journal of Advance Nursing 33:4,530-540 http://dx.doi.org/10.1046/j.1365-2648.2001.01681.x.

[13] Hinchliff, S. (2005). The practitioner as teacher ( $3^{\text {rd }}$ Ed.). Elsevier: Churchill.

[14] Kilminister, SM., Folly, BC., 2002 Reflective supervision in clinical practice settings Literature review medical Education 34:827 840

[15] Royal College of Nursing. (Undated). Clinical supervision in the workplace Guidance for occupational health nurses Retrieved at http:/www.rcn.org.uk/data/assets/pdffile007/78523/001549.pdf. 